\title{
Acute Ultrastructural Changes in the Middle Cerebral Artery Due to the Injury and Ischemia of Surgical Clamping
}

\author{
RONALD F. DODSON, YUKIO TAGASHIRA, AND LENA W-F. CHU,
}

SUMMARY: Ultrastructural changes in the zone of clamping of the middle cerebral artery of the squirrel monkey are described after application of a surgical clip. The experimental model utilized has been widely applied to the study of cerebral ischemia and possibly has relevance to clamps applied to the cerebral vessels during neurosurgical treatment of patients with cerebrovascular disorders.

RÉSUMÉ: Des changements ultrastructuraux dans la zone de pincement de artère cérébrale moyenne du singe-écureuil sont décrits suite à l'application d'une pince chirurgicale. Le modèle expérimental utilisé fut employé dans l'étude de l'ischémie cérébrale et se rapproche possiblement des pinces appliquées aux vaisseaux cérébraux durant le traitement neurochirurgical de patients avec désordres cérébro-vasculaires.
The earliest changes within the arterial wall were found in the smooth muscle (media) and accompanying fasciculi of nerves. Changes within the nerve bundles were sufficiently advanced following 4 hours of vascular clipping to suggest temporary or permanent impairment of neurogenic innervation of the cerebral vessels distal to the trunk of the vessel clipped.

Les premiers changements dans la paroi artérielle furent trouvés dans le muscle lisse (media) et les fascicules des nerfs environnants. Les changements dans les faisceaux de nerfs furent suffisamment avancés, après 4 heures de pincement vasculaire, pour suggérer une altération temporaire ou permanente de l'innervation neurogénique des vaisseaux cérébraux situés de façon distale au tronc du vaisseau pincé.
From the Departments of Neurology and Pathology, Baylor College of Medicine and The BaylorMethodist Center for Cerebrovascular Research, Houston, Texas, 77025.

Reprint requests to: Dr. Ronald F. Dodson, Assistant Professor, Department of Neurology, Baylor College of Medicine, Houston, Texas 77025

This work was supported by Grant No. 09287 from the National Institute of Neurological Diseases and Stroke, National Institutes of Health, Bethesda, Maryland 20014.

\section{INTRODUCTION}

One of the most consistently reproducible animal models for studying experimental cerebral infarction is clamping of the middle cerebral artery (MCA) (Hudgins and Garcia, 1970; Sundt and Waltz, 1966). The clamps are usually those used in neurosurgery for treating cerebrovascular disorders such as ruptured aneurysm. After experimental clipping of the middle cerebral artery, the cerebrovascular changes mimic the hemodynamic, morphological and metabolic responses resulting from naturally occurring stroke in man. Numerous investigators have used this animal model for the study of ischemic effects on the brain.

Morphological changes of intimal (endothelial) involvement have been reported in studies of larger vessels (aorta and common carotid) following injury by suture (Webster, Bishop and Geer, 1974a, b.), ligation (Hoff, McDonald and Hays, 1968), and clipping (Kawamura et al., 1974; Nelson 1973; Nelson et al., 1975). However, no reports are available of the ultra-structural changes following injury to the entire wall of an artery due to clipping and the subsequent changes which occur in accompanying nerve fibers.

\section{METHOD}

Adult squirrel monkeys were used. After being lightly anesthetized (sodium pentobarbital), the animals were subjected to a transorbital surgical procedure (Hudgins and Garcia, 1970) to expose the right middle cerebral artery at the M-I segment (Krayenbuhl and Yasargil, 1968). A Heifetz clip was then placed on this area of sphenoidal segment for respective periods of 


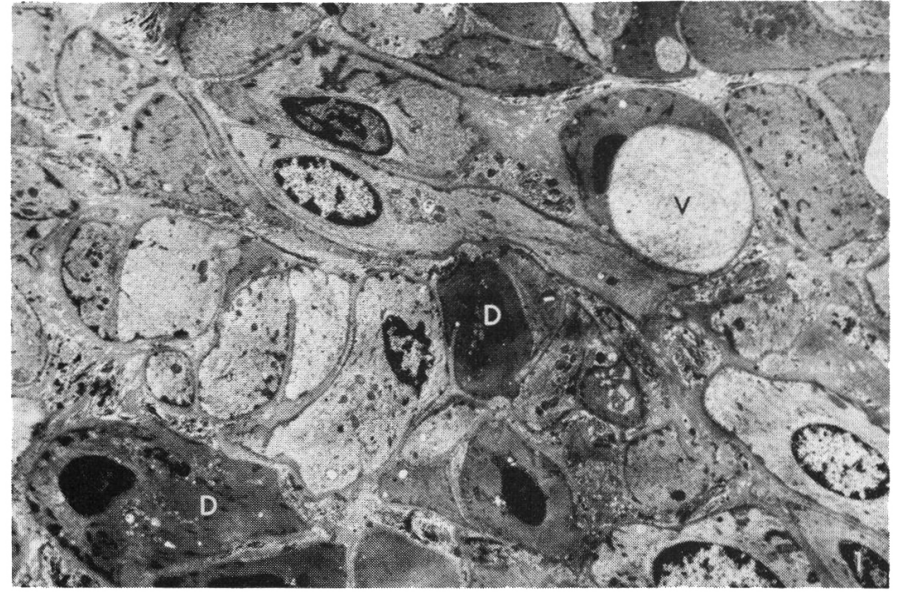

Figure 1-Large intracellular vacuoles (V) and abnormal density of smooth muscle cells (D) are seen in the media in the zone where the clip was applied. One-half hour occluded animal $(x 5,200)$.

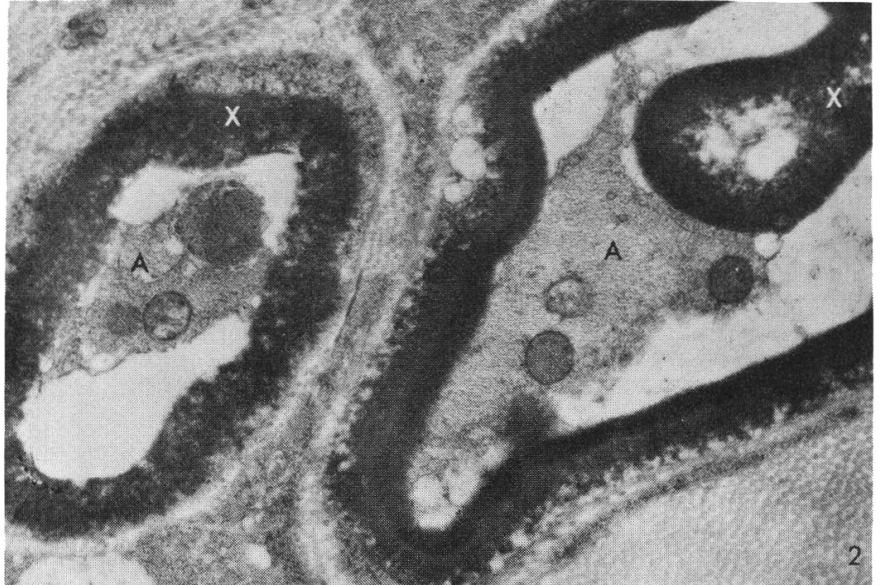

Figure 2-Neural response as well as Schwann cell involvement is reflected in this nerve bundle from the same region of the artery as in Figure 1. Granular degeneration of the myelin sheath (X) as well as axonal shrinkage (A) is evident $(\mathrm{x} 21,000)$. either $1 / 2,1,2,3$, or 4 hours. Three animals were used for each time grouping with an additional three animals serving as controls. Controls were subjected to the surgical procedure but without arterial clamping.

The clip was removed at the end of the desired occlusive period and the animals were perfused through a cannula clamped into the left ventricle. The right atrium served as the site of drainage. Perfusate consisted of $3 \%$ glutaraldehyde in $0.1 \mathrm{M}$ phosphate buffer. The perfusion pressure was maintained at systolic level in order to minimize the artifacts which occur in non-perfused arteries (Haudenschild, Baumgartner and Studer, 1972). Perfusate flow was maintained until $500 \mathrm{mls}$ of solution had passed through the circulatory system of the animal. The middle cerebral arteries were carefully dissected from the clipped (right) side and the non-involved (left) side. The clipped artery was sampled at three locations $-6 \mathrm{~mm}$ proximal to the clipped area, $6 \mathrm{~mm}$ distal to the clipped area, and the immediate area of the clip.

The specimens were then placed in the glutaraldehyde/phosphate fixative for an additional 12 hours, washed in two buffer rinses, and post-fixed for 4 hours in a $1 \%$ osmium tetroxide $/ 0.1 \mathrm{M}$ phosphate solution. Following ethanol dehydration, embedment was carried out in Spurr embedding media (Spurr, 1969).

Semi-thin plastic sections were stained with Toluidine blue and scanned by light microscopy. Thin sections were evaluated with an RCA-EMU-4 electron microscope.

\section{RESULTS}

The arteries and associated nerve fibers from the left side of the occluded animals as well as from both sides in the sham operated animals contained no morphological variations from those of the normal M-I segments of the middle cerebral artery of the squirrel monkey (Dodson, Tagashira and Chu, 1975).

The tissue alterations for each clipped group will be reported as follows, based on the respective intervals of occlusion.

\section{One-Half Hour Occluded Group}

The predominant changes within the arterial wall were in the media. The two types of changes in the smooth muscle were increased density of the cytoplasmic ground substance, and/or large intramuscular vacuoles (Fig. 1). Changes in the medial layer were most prominent in the proximal and clipped areas and random degeneration of some myelinated fibers was present in neural compartments (Fig. 2). The periodicities of the myelin sheaths were often found to be replaced in part by a granular amorphic substance (Fig. 2). In the more advanced regions of degeneration, axonal shrinkage was also observed. Unmyelinated fibers were found to be stable, and neural changes were greater distal to the clip and were minimal in the proximal region.

\section{One Hour Occluded Group}

The proximal areas contained vacuoles within the medial layers similar to the $1 / 2$ hour group (see above). The neuronal bundles contained Schwann cell changes (both intramyelin and intracellular vacuolization) as well as axonal shrinkage.

In the region of the clip, intimal changes consisted of endothelial breakdown and platelet adhesion. Extracellular pockets of edema were commonly found within the arterial wall. Intracellular vacuoles were seen in the media. Neuronal alterations varied, not only from bundle to bundle but also within the same bundle (Fig. 3). Neural degeneration was more advanced and widespread than in the $1 / 2$ hour group.

The distal area of the artery contained comparatively fewer changes than the other two regions. A few vacuoles were observed in the medial layer. Alterations within the nerve bundles were limited to the 


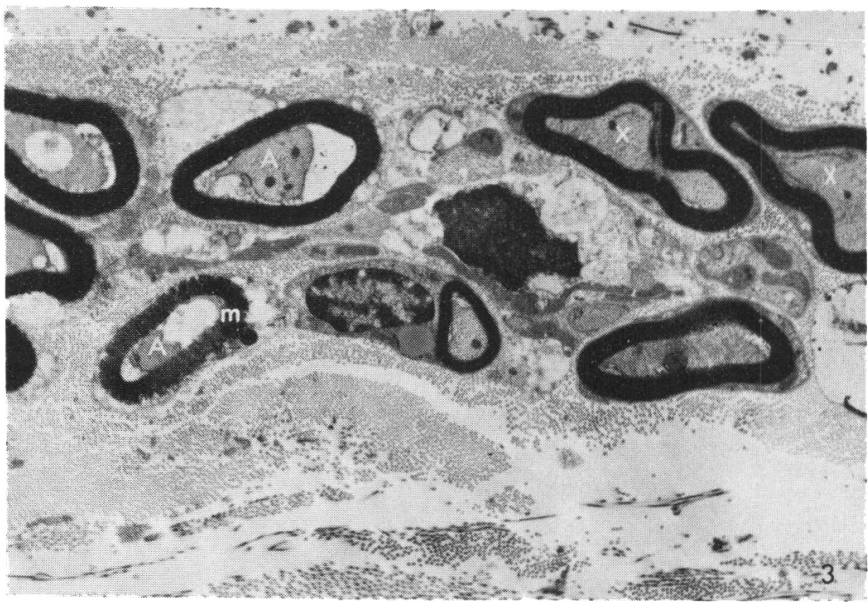

Figure 3-Changes within a periadventitial nerve bundle, which lies in the region of the clip, include axonal shrinkage (A), and/or myelin granulation $(\mathrm{m})$ adjacent to morphologically intact fibers $(\mathrm{X})$. One hour occluded animal $(\mathrm{x} 2,500)$.

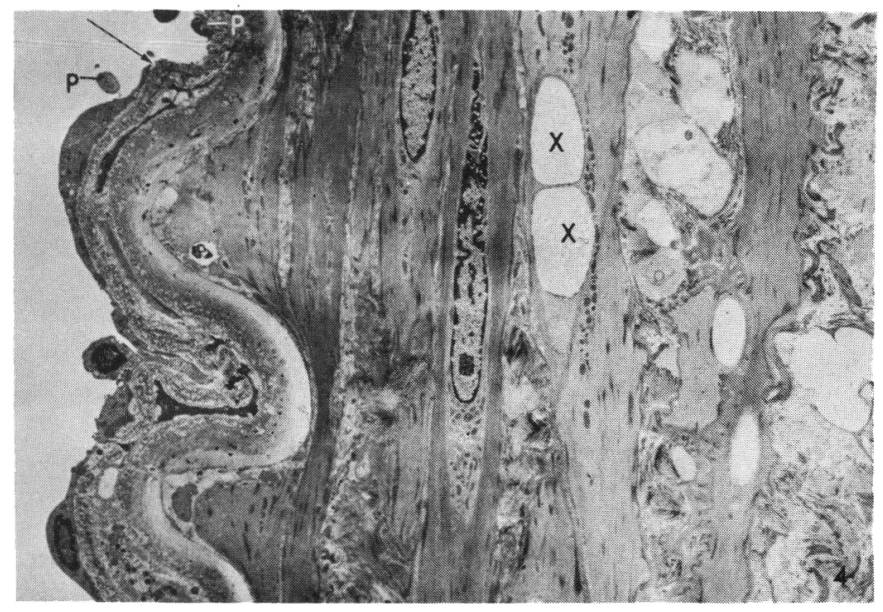

Figure 4-View of the wall from a two hour occluded animal shows endothelial damage (arrow), platelet deposition (P), as well as extensive vacuolization (X) of the media layer. Clipped region. $(x 7,200)$. myelin sheaths, consisting of bulges within the sheath as well as disruption of lamellar periodicity.

\section{Two Hour Occluded Group}

A few vacuoles were found in the medial layer of the proximal sample and only minimal myelin involvement was noted in the nerve bundles.

In the area of the clip, large intramuscular vacuoles were commonly observed on the adventital side of the medial layer. Dense smooth muscle cells with or without vacuolar involvement were also seen. Platelet deposition was a common finding at the endothelialintimal interface (Fig. 4). This relationship ranged from adherence in some regions to a continuous thin layer of platelets in other areas. Some subendothelial white blood cells were also evident.

Severe alterations were noted in some nerve bundles while varying morphological states were observed within the other bundles. Myelin sheath structures became rearranged into membrane swirls or separated into lamellar packets; intra-axonal reactions consisted of shrinkage and increased numbers of vacuolar constituents. Vacuoles were also common within the unmyelinated fibers and Schwann cell cytoplasm.

The arterial sections distal to the clip contained only a few abnormal features. Some vacuolar involvement was seen in the medial layers, and minimal alterations were seen within the myelin sheaths of the nerve bundles.

\section{Three Hour Occluded Group}

Changes in the arterial wall and in neural components were of the same nature and extent as reported in the proximal region of the 2 hour group.

The responses in the region of the clip were more evident than in the groups with shorter periods of occlusion. Platelet adherence was widespread at the degenerating endothelial lining. Edematous pockets were present in the subendothelial regions as well as between some layers of the smooth muscle. The myofilaments and other structural elements of some muscle cells were displaced or replaced by large centrally located vacuoles which contained membranous swirls and granular material. Diapedesis was evident in the wall as reflected by the presence of numerous white blood cells.

The nerve bundles contained extensive alterations as did the arterial wall. Axonal compartments of myelinated and unmyelinated fibers were often represented by small clumps of dense material. Schwann cell involvement was expressed by myelin degeneration and by changes within their perikarya, such as cytoplasmic loss of organelles and peripheral clumping of chromatin within the karyoplasm.

The distal region was characterized by the same type of endothelial degeneration and platelet interaction as described in the clipped area (Fig. 5). Medial changes were not as widespread but were of the same nature (vacuolar and increased cytoplasmic density). Diapedesis was not as common in this area as it was in the clipped region.

Widespread degeneration was seen within the nerve bundles. As in the clipped area, both myelinated and unmyelinated fibers were replaced with amorphous material (Fig. 6). The epineurium, endoneurium, and Schwann cell components lost most of their recognizable integrity.

\section{Four Hour Occluded Group}

Proximal response was no more advanced in this group than in the 2 and 3 hour sections. Predominant features consisted of platelet interaction of the endothelial interface, vacuoles within the media, and myelin sheath alterations in the nerve bundles.

As in the 3 hour group, dramatic changes were evident in the region of the clip. Extensive platelet interaction with the remnants of a highly damaged endothelial region 


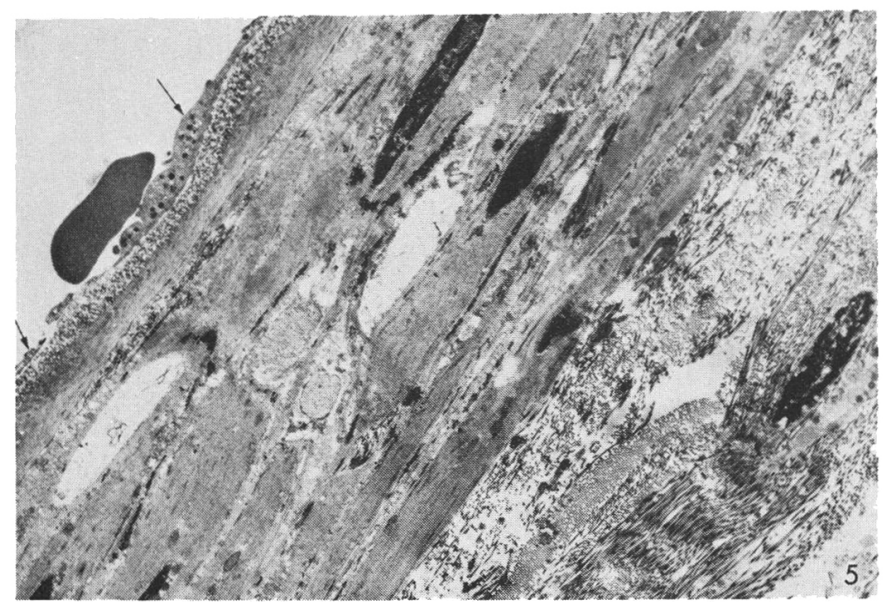

Figure 5-The region distal to the clip in this three hour occluded animal shows necrotic activity within all layers of the wall. A prominant layer of platelets (arrows) lines the luminal space $(x 5,000)$.

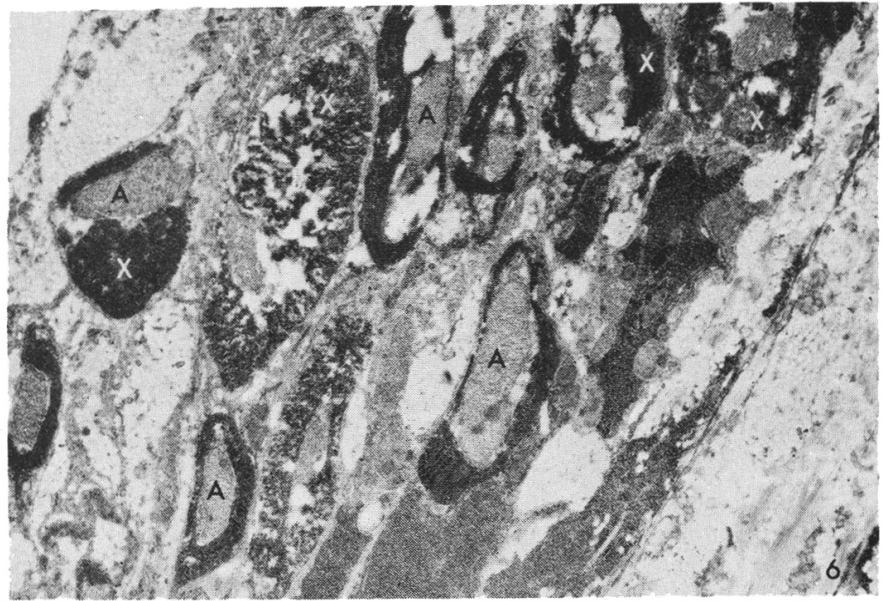

Figure 6-This field of an area distal to clip contains the remnants of an adventital nerve bundle. Amorphic substance replaces the myelin lamella $(X)$ while the axonal compartments (A) are also in a necrotic state. Three hour occluded animal $(x 15,000)$. was commonly seen. Edematous pockets were found throughout the wall. Myofilaments were displaced by large intracellular vacuoles and loss of structural integrity was evident within the nerve bundles. Dense regions of crenated axons and scattered myelinated fragments were noted.

Greater alterations were present in the distal region. The luminal surface consisted of platelets and white blood cells which replaced the endothelial components in most areas
(Fig. 7). Scattered, smooth muscle cells were identifiable in the medial layer, and the remainder of this layer was comprised of collagenous fibers, elastin components, and various phagocytic cell types. Neural components are recognizable only as dense regions with associated myelinated fragments (Fig. 8).

\section{DISCUSSION}

As a result of the technical approach used in this model, arterial regions were exposed to a combina- tion of three insults - hemostasis and resulting hemoconcentration, trauma and ischemia (Meyer, 1958).

It would appear from this study that some division of pathological events in each area can be related to the length of the occlusion. In those animals occluded for $1 / 2$ hour or 1 hour, changes were more prominent in the proximal and clipped areas. These changes were consistent with the myonecrosis shown in experimental vasospasm (Alksne, 1974; Alksne and Greenhoot, 1974) while the dis-

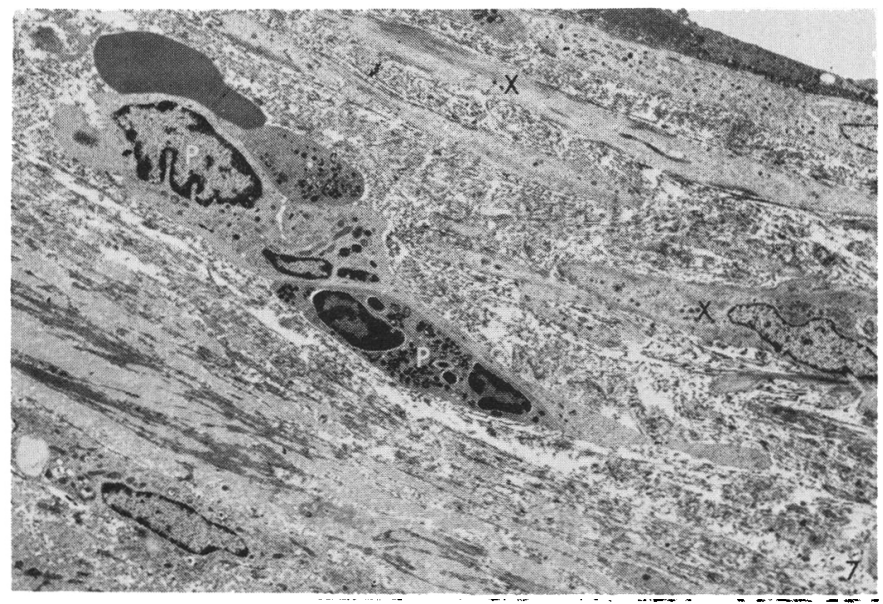

Figure 7-Extensive alterations within the arterial wall are shown in this section. Abundant phagocytic cell types $(P)$ and necrotic debris comprise most of the field. A few severely altered smooth muscle cells are recognizable $(X)$. A dense border comprised of platelets and unidentifiable cell types line the lumen. Distal to the clip, four hour occluded animal $(x 4,200)$.

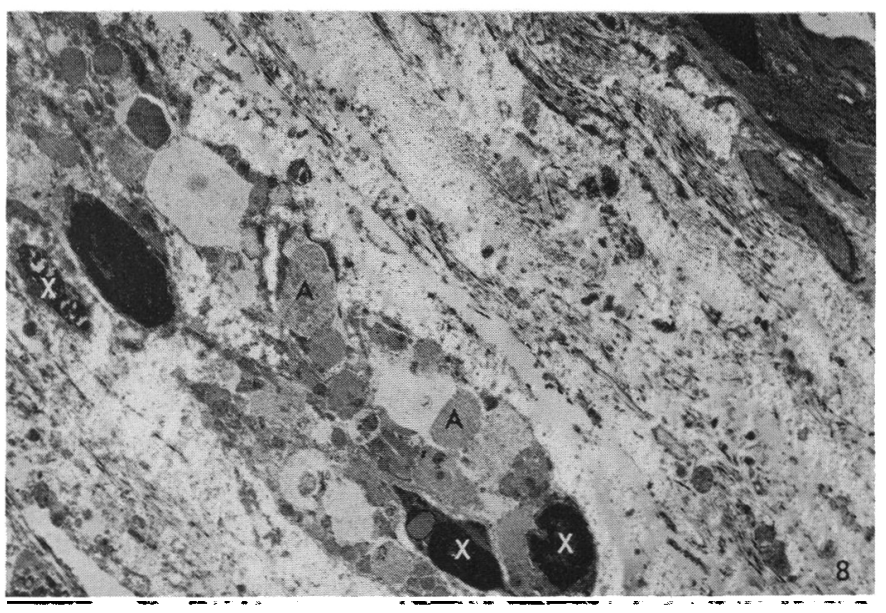

Figure 8-The neuronal elements in the region of Figure 7, are represented by the adventitial bundle in this field. Dense material characterizes the remains of the myelin sheaths (X) while amorphous granular regions are the presumed remnants of the axonal structures $(\mathrm{A})$. Four hour occluded animal distal to the clip $(X 6,800)$. 
tal regions did not contain intimal changes previously reported for acute response to ischemia (Hoff, McDonald and Hayes, 1968). It was concluded that the initial alterations were induced by chemical substances released from the damaged nerves and stagnant vascular elements and/or direct surgical trauma to the wall.

In the animals subjected to 2,3 , or 4 hour occlusions, major alterations were found in all layers of clipped and distal sections. The advanced ischemic changes of the intimal lining were in accord with intimal responses in distal areas of the surgically occluded carotid arteries ( Nel son et al., 1975). The overall topography of the distally treated region of the arterial wall in the 2,3 , or 4 hour groups showed greater degenerative changes than in the proximal region. Findings in the distal areas were interpreted as the result of ischemic influence coupled with traumatically induced changes. This concept was reinforced since proximal and distal areas of the wall were sampled at equal distances from the clip, thus the traumatic changes should affect both equally.

Neural changes are most evident in the clipped and distal areas of the 2,3 , and 4 hour groups. Myelinated fibers show greatest susceptability in the 3 and 4 hour groups where involvement is sufficiently extensive to include all elements (myelinated axons, unmyelinated axons, Schwann cells, and epineural sheath) of the nerve bundles.
In these acute studies, alterations in the arterial wall point out morphological changes which suggest certain undesirable features in the use of this model for acute and chronic experiments. Degeneration of the vascular innervation might be expected to significantly alter autoregulatory functions which are inherently important to such cerebral vessels.

\section{ACKNOWLEDGEMENTS}

The authors express their appreciation to Dr. John Stirling Meyer for helpful guidance throughout this project.

\section{REFERENCES}

ALKSNE, J. F. (1974). Myonecrosis in chronic experimental vasospasm. Surgery, 76, 1-7.

ALKSNE, J. F., and GREENHOOT, J. H. (1974). Experimental catecholamineinduced chronic cerebral vasospasm. Journal of Neurosurgery, 41, 440-445.

DODSON, R. F., TAGASHIRA, Y., and CHU, L. W-F. (1975). The ultrastructure of the middle cerebral artery and its associated nerve fibers in the squirrel monkey and baboon. Tissue and Cell, 7, 171-180.

HAUDENSCHILD, C., BAUMGARTNER, H. R., and STUDER, A. (1972). Significance of fixation procedure for preservation of arteries. Experientia, 28, 828-831.

HOFF, H. F., McDONALD, L. W., and HAYES, T. L. (1968). An electron microscope study of the rabbit aortic intima after occlusion by brief exposure to a single ligature. British Journal of Experimental Pathology, XLIV, 68-73.

HUDGINS, W. R., and GARCIA, J. H. (1970). Transorbital approach to the middle cerebral artery of the squirrel monkey: A technique for experimental cerebral infarc- tion applicable to ultrastructural studies. Stroke, 1, 107-111.

KAWAMURA, J., GERTZ, S. D., SUNAGA, T., RENNELS, M. L., and NELSON, E. (1974). Scanning electron microscope observations on the luminal surface of the rabbit common carotid artery subjected to ischemia by arterial occlusion. Stroke, 5, 765-774.

KRAYENBUHL, H. A., and YASARGIL. M. G. (1968). Cerebral Angiography, 55, Butterworth and Company, Limited, London.

MEYER, J. S. (1958). Importance of ischemic damage to small vessels in experimental cerebral infarction. Journal of Neuropathology and Experimental Neurology, 17, 571-585.

NELSON, E. (1973). Endothelial ischemia as studied by correlated scanning and transmission electron microscopy and by fluorescent antibody staining, in: Atherogenesis I1, Excerpta Medica, Amsterdam, (Shimamoto, T., and Numano, F., eds.), 66-75.

NELSON, E., SUNAGA, T.. SHIMAMOTO, T., KAWAMURA, J.. RENNELS, M. L., AND HEBEL, R. (1975). Ischemic carotid endothelium: Scanning electron microscopical studies. Archives of Pathology, 99, 125-131.

SPURR, A. R. (1969). A low-viscosity epoxy resin embedding medium for electron microscopy. Journal of Ultrastructure Research, 26, 31-43.

SUNDT, T. M., and WALTZ, A. G. (1966). Experimental cerebral infarction: Retroorbital, extradural appraoch for occluding the middle cerebral artery. Proceedings of the Mayo Clinic, 41, 159-168.

WEBSTER, W. S., BISHOP, S. P., and GEER, J. C. (1974a). Experimental aortic intimal thickening I. Morphology and source of intimal cells. Animal Journal of Pathology, 76, 245-264.

WEBSTER, W. S., BISHOP, S. P., and GEER, J.C. (1974b). Experimental aortic intimal thickening II. Endothelialization and permeability. American Journal of Pathology, 76, 245-264. 